\title{
ПРОБЛЕМЫ И ПЕРСПЕКТИВЫ РАЗВИТИЯ ТРУДА В КОНТЕКСТЕ ПЕРЕХОДА К ЗЕЛЁНОЙ ЭКОНОМИКЕ
}

\author{
(C) 2018 Ходыкин Александр Владимирович \\ Самарский национальный исследовательский университет им. академика С.П. Королева \\ 443011, Самара, улица Академика Павлова, 1 \\ E-mail: avhod@yandex.ru
}

В работе исследованы экологические, экономические и социальные аспекты заявленного на международном уровне глобального перехода к зелёной экономике. На базе международных документов проанализированы проблемы и перспективы развития трудовой сферы в контексте глобального перехода к зелёной экономике.

Ключевые слова: зелёная экономика, рынок труда, экология, развитие, проблемы, перспективы, международное сообщество, зелёное рабочее место.

Рост производственных мощностей и безграничность потребностей человека в сочетании с ограниченностью ресурсов планеты способствуют ухудшению экологической ситуации на Земле и развитию глобального экологического кризиса. Так, согласно данным отчёта Всемирного фонда природы за 2010 год, значение индекса живой планеты, оценивающего богатство биоразнообразия, упало на $30 \%$ по сравнению с 1970 годом [1]. В то же время потребность человечества в природных ресурсах с 1966 года увеличилась почти в 2 раза [2]. По данным Международного энергетического агентства за 2016 год, ежедневно в мире 18 миллионов человек умирают по причинам, связанным с загрязнением воздуха [3]. В такой ситуации значимым ресурсом для улучшения экологической ситуации на Земле становится переход на зелёную экономику. Решение о глобальном переходе на зелёную экономику на мировом уровне было принято ещё в 2010 году на 40 Всемирном экономическом форуме в Давосе.

Зелёная экономика - это экономическая система, основанная на комплексном сочетании в хозяйственной деятельности человека принципов ресурсосбережения и бережного отношения к природе, соблюдения связанных с трудовой деятельностью прав человека и повышения экономической эффективности деятельности. Зелёная экономика предполагает необходимость создания зелёных рабочих мест. В Докладе МОТ за 2008 год термин «зелёное рабочее место» определяется как место работы в промышленности, сельском хозяйстве, в научно-исследовательской или административной деятельности, предполагающее работу, способствующую сохранению или восстановлению окружающей среды [4]. Российские экономисты Е.А. Войкина и И.М. Потравный выделяют следующие критерии зелёных рабочих мест: экономические (достойная зарплата работников, высокий уровень производительности труда, низкая материалоёмкость), социальные (социальная защита и соблюдение трудовых прав работников), технические и технологические (отсутствие вредных и опасных условий труда, использование современного оборудования), экологические (минимизация отрицательного воздействия на окружающую среду) [5].

Перспективы развития труда в рамках перехода к зелёной экономике представлены в докладе МОТ от 2018 года, авторы которого предсказали, что переход к зелёной экономике позволит создать 24 миллиона новых рабочих мест к 2030 году, в то время как упразднено будет лишь 6 миллионов рабочих мест [6]. При этом необходимо отметить, что качество создаваемых рабочих мест будет значительно выше качества упраздняемых. Создание новых рабочих мест призвано обеспечить кадрами такие ключевые для формирования зелёной экономики процессы, как переход от углеводородов к альтернативным источникам энергетики; создание, развитие и восстановление экосистем; очистка воздуха, воды, почв; совершенствование ведения сельского и лесного хозяйства, туризма и промышленности.

Однако несмотря на всю свою перспективность переход к зелёной экономике сопряжён и с рядом проблем, решение которых определит его эффективность и способность достичь поставленных целей. 
Во-первых, как правильно отмечает П.В.Трифонов, на сегодняшний день многие виды работ, которые должны стать зелёными, по факту к таковым отнести нельзя из-за их несоответствия ни экологическим, ни экономическим, ни социальным требованиям к зелёным рабочим местам. Взять, к примеру, деятельность по переработке отходов. В принципе это должна быть типичная зелёная деятельность, однако на практике она часто бывает сопряжена с загрязнением окружающей среды, вредным и опасным для рабочих трудом, который к тому же крайне плохо оплачивается [7]. Необходимым условием решения данной проблемы является совместная деятельность по охране труда и охране окружающей среды со стороны международных организаций, государственных органов, законодательных институтов, общественных организаций и институтов гражданского общества. Особенно такая деятельность необходима в слабо развитых и развивающихся странах.

Во-вторых, чтобы приобрести глобальный масштаб, переход к зелёной экономике должен состояться в максимальном количестве стран и затронуть максимальное количество людей во всём мире, однако таких стран и количества, вовлечённых в зелёную экономику людей по всему миру в настоящее время явно недостаточно. Отставание слаборазвитых и развивающихся стран, как в экологическом, так и в экономическом и социальном плане всё ещё слишком велико для их перехода к зелёной экономике. Экономика таких стран основывается на низкоэффективном производстве, загрязняющем природу и не дающем возможностей для развития, как экономики, так и занятых в ней людей, в результате чего достичь глобального распространения достойных условий труда пока не удаётся. Что касается развития человека, то имеется значительное отставание слаборазвитых стран по этому показателю. Так, значения индекса развития человеческого потенциала (ИРЧП), варьирующиеся от 0 до 1, в наиболее и наименее развитых странах различаются почти в 3 раза [8]. Примерно такой же разрыв между развитыми и неразвитыми странами остаётся по индексу экологической эффективности [9]. Затрудняет переход к зелёной экономике и высокий уровень глобального социально-экономического неравенства между людьми, ставшего следствием широкого распространения рабочих мест с низкой оплатой труда на фоне стремительно возросших доходов наиболее богатой части населения. По данным исследований ООН (исследовались 166 стран, в которых проживает 97\% населения Земли) уровень глобального социально-экономического неравенства с 1970-х до середины 2000-х годов значительно вырос, а после середины 2000-х не снижается и остаётся на стабильно высоком уровне [10]. Актуальной остаётся проблема гендерного неравенства: среднемировое значение индекса гендерного неравенства (ИГН) составляет 0,441 [11]. Это означает, что из-за связанных с гендерным неравенством проблем в среднем в мире не используется около 44\% человеческого потенциала. Учитывая вышесказанное, можно заключить, что сокращение различных форм ресурсного неравенства и содействие в развитии отстающим странам является важным условием формирования глобальной зелёной экономики. Проблема избыточного неравенства в различных его видах остаётся труднопреодолимым препятствием для достижения составляющих ядро зелёной экономики экологических, экономических и социальных целей, как на уровне отдельных государств, так и на международном уровне.

В-третьих, особо актуальной остаётся проблема экспорта наиболее неэкологичных и загрязняющих окружающую среду видов производства из развитых стран в слаборазвитые. На то есть две основные причины:

- во-первых, затраты на рабочую силу в слаборазвитых странах в разы ниже, т.к. там можно платить более низкую зарплату и не тратиться на обеспечение достойных условий труда для работников;

- во-вторых, в слаборазвитых странах значительно ниже требования $\mathrm{K}$ экологичности производства, что позволяет его владельцам экономить на обеспечении соответствия производства строгим экологическим стандартам развитых стран. В результате привлечь к ответственности разрушающих природу и нарушающих права человека владельцев производства по законам развитых стран не получается.

Для решения этой проблемы необходимо совершенствование системы международного права и правоприменительной практики, а именно создание единых международных экологических стандартов и стандартов достойного труда и разработка механизмов их реализации в любой точке мира. Государства должны получить право привлекать к ответственности своих 
граждан за их деятельность в любой точке мира, а международному сообществу необходимы рычаги давления на страны, пренебрегающие этим правом в отношении лиц, нарушающих экологические стандарты и права человека. В отношении корпораций, нарушающих экологические стандарты и права человека, должны активно применяться международные санкции.

Развитие и распространение экологичных технологий сдерживается их высокой стоимостью и недостаточным уровнем инвестиций в их разработку и распространение. Особенно сильно эта проблема проявляется на этапе разработки и начального внедрения новой экологичной технологии, т.е. на этапах, когда она пока ещё дорого стоит и представляется экономически невыгодной. Кроме того, для представителей крупного бизнеса, работающего в сфере неэкологичных технологий, не выгодно развитие более экологичной промышленности, которая потенциально более конкурентоспособна, и они в лучшем случае не будут инвестировать в ресурсосберегающие технологии, а в худшем могут препятствовать их развитию. Для повышения инвестиционной привлекательности экологичных технологий целесообразно сочетание административных мер (к примеру, ужесточение наказаний за превышающее нормы по загрязнению окружающей среды производство) с мерами экономического стимулирования (например, повышение налоговой нагрузки на углеводородную энергетику с использованием полученных средств для финансирования ресурсосберегающих проектов).

Несмотря на все представленные выше проблемы перехода к зелёной экономике, завершить их анализ можно всё же на оптимистичной ноте: мы можем констатировать, хоть и не такое значительное, как нам хотелось бы, но всё же улучшение значения большинства проблемных показателей за последние годы. Снижается количество стран с низким развитием человеческого потенциала, уменьшается гендерное неравенство, растёт доля возобновляемых источников в мировом энергопотреблении [12]. Однако мы должны понимать, что для достижения целей глобального перехода на зелёную экономику этого явно не достаточно. Глобальный переход к зелёной экономике должен стать исходным скачком на новый уровень природопользования, хозяйственной деятельности и социальной сферы. Поэтому предстоит ещё очень много сделать для улучшения экологических, экономических и социальных показателей развития человечества.

\section{Библиографический список}

1. Living Planet Report / Доклад Всемирного фонда природы о Живой планете. - 2010. [Электронный ресурс]. URL: http://www.wwf.ru/recources/publ/book/436 (дата обращения: 10.10.2018).

2. Захарова T.В. «Зелёная» экономика как новый курс развития: глобальный и региональный аспекты // Вестник Томского гос. ун-та. Экономика. 2011. С. 28-38.

3. Energy and Air Pollution: World Energy Outlook Special Report.Paris. - 2016. [Electronic resource].-URL: www.iea. org/publications/freepublications/publication/WorldEnergyOutlookSpecial Report2016EnergyandAirPollution. pdf (Accessed 10.10.2018).

4. Green Jobs: Towards decent work in a sustainable, low-carbon world. UNEP, ILO, OIE, ITUC, 2008. - 2008. [Electronic resource].- URL: http://www.ilo.org/wcmsp5/groups/public/--ed_emp/--emp_ent/documents/publication/wcms_158727.pdf (Accessed 07.10.2018).

5. Войкина Е. А., Потравный И.М. Зеленая занятость и рынок труда при формировании экологически ориентированной экономики // Вестник Санкт-Петербургского университета. Экономика. - 2018. Т. 34. Вып.2. C. 217-240. - 2018. [Электронный ресурс]. - URL: https://doi.org/10.21638/11701/spbu05.2018.202 (дата обращения: 07.10.2018).

6. World Employment and Social Outlook 2018: Greening with jobs.- 2018. [Electronic resource].- URL: https://www.ilo.org/wcmsp5/groups/public/--dgreports/--dcomm/--publ/documents/publication/ wcms_628654.pdf (Accessed 07.10.2018).

7. Трифонов П.В. Зелёные рабочие места - основа эколого-ориентированной экономики в XXI веке // Стратегии бизнеса. -2015 . № 3. С. 21-27.

8. Human Development Indices and Indicators. Special Report. - 2018. [Electronic resource]. - URL: http://hdr.undp. org/sites/default/files/2018_human_development_statistical_update.pdf (Accessed 07.10.2018).

9. Рейтинг стран мира по рейтингу экологической эффективности: Yale Center for Environmental Law and Policy: The Environmental Performance Index 2018. - 2018. [Электронный ресурc]. - URL: https://gtmarket.ru/ ratings/environmental-performance-index (дата обращения: 07.10.2018). 
10. Обзор мирового экономического и социального положения, 2014 год: сокращение неравенства в интересах устойчивого развития. - 2014. [Электронный ресурс]. - URL: http://www.un.org/en/development/desa/policy/ wess/wess_archive/2014wess_overview_ru.pdf (дата обращения: 10.10.2018).

11. Статистические данные ООН: Gender Inequality Index. - 2018. [Электронный ресурс]. - URL: http://hdr.undp. org/en/composite/GII (дата обращения: 07.10.2018).

12. О возобновляемых источниках в производстве электроэнергии.- 2018. [Электронный pecypc].- URL: https://ecotechnica.com.ua/energy/3349-dolya-vie-v-proizvodstve-elektroenergii-v-mire-dostigla-25.html (дата обращения: 07.10.2018). 